\title{
Detailed Analysis of Routing Protocols with Different Network Limitations
}

\author{
Mohsin MASOOD, Mohammed ABU HELALA, Ivan GLESK \\ Electronics and Electrical Engineering Department, University of Strathclyde, Royal College \\ Building, Glasgow, UK
}

In network communication field, routing protocols have got a significant role which are not only used in networks to handle the user data but also monitors the various network limitations. Dynamic routing protocols such as OSPF, EIGRP and RIP are used for forwarding user data to its destination by instantly detecting the network limitations. These network limitations can be considered as topological changes, congestion, packet delays/ loss because of protocols higher number of packets. Thus, it becomes a challenging task for researchers in order to use such dynamic routing protocol that fulfills the network requirements. Hence, each routing protocol has its own characteristics such as convergence, metric, routing table etc. So as each one of them performs differently with each other in various network environments. This paper presents a comprehensive study of these three mentioned dynamic routing protocols. Experiments have been conducted with various network limitations by using OPNET tool that monitors the performance of each routing protocols. The simulated results are analyzed in detail to get a clear understanding of each protocol's performance which will lead to choose the specific protocol for various network environments.

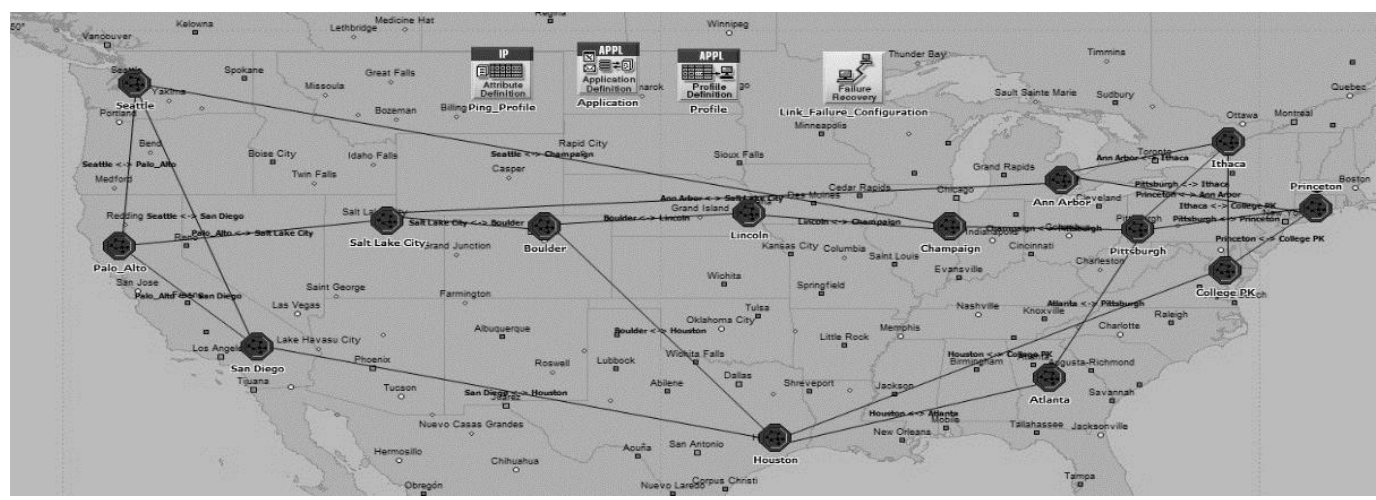

Figure 1. NSFnet 14 nodes Topology

\section{REFERENCES}

[1] Albrightson, B., Garcia-Luna-Aceves, J. and Boyle, J. (2001). EIGRP routing protocol based on distance vectors. Journal of internetworking.

[2] Bright, A., Adamu, M., Franklin, A. and Asante, M. (2016). Performance Analysis of Enhanced Interior Gateway Routing Protocol (EIGRP) Over Open Shortest Path First (OSPF) Protocol with Opnet. International Journal of Advanced Computer Science and Applications, 7(5).

[3] H, P. (1998). Convergence Behavior of RIP and OSPF Network Protocols. High-Performance Communication Networks. Morgan Kaufmann Publisher.

[4] Hinds, A., Atojoko, A. and Ying Zhu, S. (2013). Evaluation of OSPF and EIGRP Routing Protocols for IPv6. IJFCC, pp.287-291.

[5] Rakheja, P., kaur, P., gupta, A. and Sharma, A. (2012). Performance Analysis of RIP, OSPF, IGRP and EIGRP Routing Protocols in a Network. International Journal of Computer Applications, 48(18). 